\title{
STUDY OF DROUGHT TOLERANCE IN RECOMBINANT INBRED LINES (RIL $)$ DERIVED FROM THE CROSS OF BPT-5204/ SAHBHAGI DHAN
}

\author{
SONALI KAR ${ }^{1}$, D. N. SINGH ${ }^{2}$, KRISHNA PRASAD ${ }^{3}$, ANITA PANDE $^{4} \&$ Z. A. HAIDER ${ }^{5}$ \\ ${ }^{1}$ Research Scholar, Department of Plant Breeding and Genetics, Birsa Agricultural University, Ranchi, Jharkhand, India \\ ${ }^{2}$ Chief Scientist cum Principal Rice Breeder, Department of Plant Breeding and Genetics, BAU, Ranchi, Jharkhand, India \\ ${ }^{3}$ Assistant Professor, Department of Plant Breeding and Genetics, Birsa Agricultural University, Ranchi, Jharkhand, India \\ ${ }^{4}$ Assistant Professor, Department of Biotechnology, BAU, Ranchi, Jharkhand, India \\ ${ }^{5}$ Chairman, Department of Plant Breeding and Genetics, Birsa Agricultural University, Ranchi, Jharkhand, India
} \begin{abstract}
Drought is referred to as low-moisture stress, or is a form of abiotic stress, which is a challenge, posed by the environment to the survival and productivity of a crop that occupies a large area. The development of drought tolerant rice varieties is considered a feasible option to counteract drought stress. However, the breeding efforts to develop varieties with improved productivity are being hindered, due to lack of understanding of inheritance of drought tolerance and poor understanding of physiological basis of yield under water stress. The aim of the present study was to select drought tolerant genotypes from the $F_{6}$ population of a cross between BPT-5204 (drought susceptible) and SahbhagiDhan (drought tolerant) in lowland ecology by the use of morphological markers and MAS (Marker Assisted Selection), with SSRs available in the public domain. Screening of Eight Hundred and Ten Recombinant Inbred Lines (RILs) for drought was carried out under rainout condition. Molecular studies revealed the presence of maximum of 4 QTLs for drought in a single genotype. However, the drought QTLs detected was on chromosomes 1, 3, 4, 5, 6 and 7. These QTLs were linked to various characters like plant height, panicle length, grain yield, root thickness, root length, root volume, root to shoot ratio, days to $50 \%$ flowering, biomass, harvest index and test weight.
\end{abstract}

KEYWORDS: Rice, Drought, Oryza \& Microsatellites

Received: Jun 18, 2017; Accepted: Jul 07, 2017; Published: Jul 11, 2017; Paper Id.: IJASRAUG201722

\section{INTRODUCTION}

Drought is the major constraint to rice production in rain fed areas across Asia and sub-Saharan Africa. At least 23 million hectares (20\% of rice area) are potentially affected in Asia alone. Frequent droughts result in enormous economic losses and have long-term destabilizing socioeconomic effects on resource-poor farmers and communities. This directly translates to economic loss to the farmer(s), who depend on the harvest. More recently, global warming may be worsening this situation in most agricultural regions. Over 50\% of the world's rice (Oryzasativa L.) is rain fed, but these non-irrigated lands produce only a quarter of total rice output (McLean et al., 2002).Water stress has been identified as one of the major constraints to rice cultivation in rain fed lowland ecosystems, which occupy 28 per cent of rice cultivation area in Jharkhand. A wide range of traits is found to be associated with drought resistance. As a breeding objective, the plant traits that could be selected among segregants are robust and efficient root systems, well-endowed shoot system and finally grain yield. Marker-assisted selection is expected to boost the pace of crop improvement, especially for complex trait like drought. Therefore, in this study, drought tolerant genotypes were identified by MAS (Marker Assisted Selection) using SSR markers linked 
to various morphological and yield characteristics of the mapping population.

\section{MATERIALS AND METHODS}

The investigation was carried out during Kharif season 2013, at Birsa Agricultural University, Ranchi, Jharkhand. The experimental materials to be used in research are $\mathrm{F}_{6}$ generation population derived from the cross of BPT-5204(Samba Mahsuri) and Sahbhagi Dhan. Eight hundred ten recombinant inbred lines were screened for the drought tolerance in the rain out and the same set of RILs (Recombinant Inbred Lines) was also planted in the normal rain fed lowland condition. Observations of various morphological and yield contributing characteristics were recorded.

\section{Field Condition}

The eight hundred and ten recombinant inbred lines, and the parents BPT-5204 and Sahbhagi Dhan, were evaluated under rainout shelter and rain fed field conditions in the 2013 wet season. Water stress condition was imposed for 35 days during the vegetative stage. The observations on recovery were recorded after 7 days of irrigation of imposing water stress duration. The RILs showed a wide range of drought tolerance features like leaf rolling, leaf drying and recovery. In order to differentiate the highly drought tolerant, moderately drought tolerant, moderately drought susceptible and highly drought susceptible the 810 recombinant inbred lines were grouped into four groups based on their leaf rolling and leaf drying scores as per SES (Standard Evaluation System) of IRRI. Twenty RILs highly tolerant to drought condition were selected for DNA based studies. In the rain fed field condition, morphological and yield attributing characteristics were observed like plant height, days to 50\% flowering, number of effective tillers, panicle length, biomass, harvest index, grain length, grain width, LB ratio, test weight and grain yield.

\section{Genotyping}

\section{DNA Extraction and Amplification of PCR Products}

Genomic DNA was isolated from $1.0 \mathrm{~g}$ of leaf of the inbred lines using CTAB method described by Dellaportaet al. (1983). DNA extraction by $1 \%$ Cetyltrimethyl ammonium bromide (CTAB) solution in $100 \mathrm{mMTris}, 500 \mathrm{mMNaCl}$ and $50 \mathrm{mM}$ EDTA. The crude DNA obtained after purification using chloroform: isoamylalcohol was dissolved in $500 \mu 1$ of TE buffer. After RNase treatment ( $3 \mu \mathrm{l}$ of $10 \mathrm{mg} / \mathrm{ml}$ solution) for 1 hour at $37^{\circ} \mathrm{C}$ ), the DNA was then purified by Phenol: Chloroform: Isoamylalcohol (25:24:1). DNA samples were quantified on $1 \%$ agarose gel and concentration adjusted to approximately $25 \mathrm{ng}^{\mathrm{L}} \mathrm{L}^{-1}$. PCR amplification was done with a $10 \mu \mathrm{L}$ reaction mixture having $50 \mathrm{ng}$ DNA, 10x PCR buffer, $10 \mathrm{Mm}$ dNTPs, $50 \mathrm{p}$ mol primers, and $1.0 \mathrm{U} / \mu \mathrm{LTaq}$ polymerase enzyme. To resolve the PCR products, $2 \%$ agarose gels were used. Parental polymorphism survey was done between BPT-5204 and Sahbhagi Dhan with 19 rice simple sequence repeat (SSR) markers taken from already available rice genetic and sequence maps.

\section{Genotyping of BPT5204/Sahbhagi Dhan population}

$2 \%$ agarose gel was used to detect parental polymorphism using 19 SSR markers, reported to be linked to drought. Genotyping of BPT5204/Sahbhagi Dhan population was carried out with 6 polymorphic SSR markers.

\section{RESULTS AND DISCUSSIONS}

\section{Phenotypic Performance}

Under rainout condition, the recombinant inbred lines (RILs) along with the parents (BPT-5204 and Sahbhagi Dhan) and susceptible check IR20 manifested significant differences in respect of leaf rolling, leaf drying and leaf drying 
recovery. Eight Hundred Ten Recombinant Inbred Lines (RILs) were grouped into highly drought tolerant lines (score 03.0), moderately drought tolerant lines (score 3.1-5.0), moderately drought susceptible lines (score 5.1-7.0) and highly drought susceptible lines (score 7.1-9.0). Kanagaraj et al. (2010) also selected 11 RI lines, which performed well (low scores) and 12 RI lines, which performed very poorly (high scores) out of 330 RI lines and grouped into drought resistant and drought susceptible lines respectively, based on leaf rolling and leaf drying scores under water stress condition. Swain et al. (2014) studied 134 landraces that represented different geographic regions of India and a few from Indonesia and Philippines, with an SES (Standard Evaluation System) score of 0-3 in the 0-9 scale, seventy eight accessions were scored as tolerant with twelve having ' 0 ' score, eighteen with ' 1 ' and forty eight with the score ' 3 '. Of the seventy eight genotypes, thirteen had recorded yield over $1.0 \mathrm{t} /$ ha while the tolerant (CR 143-2-2) and susceptible controls (IR 20) recorded $2.70 \mathrm{t} /$ ha and zero yield, respectively. Screening of the RI lines was carried out under rainout shelter and the morphological observations were recorded in the normal rain fed low land condition. The mean data of individual lines of the population was statistically analyzed to generate overall mean and other parameters. The variability in the mean values of different drought related traits (plant height, days to 50\% flowering, number of effective tillers, panicle length, grain length, grain width, L/B ratio, test weight, grain yield, biomass, harvest index) among the RILs was distinguishable. These results were in agreement with the results of Singh et al., (2004); Manickaveli, et al., (2006), they have also reported significant variability for these traits.

\section{Genotypic Performance}

Out of the 19 SSR markers assessed, 6 were found to be polymorphic. These were RM 1349, RM 3825, RM 212, RM 232, RM 24 and RM 3.The polymorphic SSRs were further used with the 20 selected RILs, found phenotypically drought tolerant, under rainout shelter condition.

Observations on drought screening (leaf rolling, leaf drying and recovery) as well as various morphological and yield attributing characteristics under rain fed low land condition categorized the population, based on their level of drought tolerance, and thus, 20 highly drought tolerant inbred lines were further selected for the molecular studies using SSR markers linked to drought. The evaluation of the genotypes, phenotypically and genotypically showed the presence of QTLs for drought in 20 RILs. In the present study, the six polymorphic primers used with the 20 selected RILs were linked to different QTLs governing drought tolerance (Kanagarajet al. 2010). RM 1349 is reported to be linked to QTLs governing plant height (Lin et al. 2007) (drought tolerant lines were line number 122, 125, 135, 137, 152, 161, 162, 165, 179, 180, 181, 194, 205, 418, 586, 808, 809 and 810). RM 3825 is reported to be linked to QTLs for plant height, panicle length and grain yield (Boopathi, 2004; Beena, 2005) (drought tolerant lines were line numbers 4, 165, 193 and 808). RM 212 has been reported to be linked to QTLs for days to 50\% flowering, biomass, harvest index, test weight, plant height, panicle length, grain yield and number of effective tillers (Price et al. 2000; Babu et al. 2003; Kamoshita et al. 2002; Bernier et al. 2007; Hittalmani et al. 2003) (drought tolerant line was line number 193). RM 232 is reported to be linked to QTLs for test weight (Lin et al. 2007) (drought tolerant lines were line numbers 122, 125, 135, 137, 152, 161, 162, 179, 180, 181, 193, 194, 205, 418, 586, 809 and 810). RM 24 is reported to be linked to QTLs for plant height (Lin et al. 2007) (drought tolerant lines were line numbers 193 and 808). RM 3 is reported to be linked to the QTLs for yield (Lin et al. 2007) (drought tolerant lines was line number 193).Venuprasad et al. (2002) and Steele et al. (2006) 


\section{CONCLUSIONS}

The RIL population derived from the cross of BPT 5204 and Sahbhagi Dhan was screened in rainout shelter, evaluated under rain fed lowland condition and analysed using molecular (SSR) markers. Parental polymorphism was performed using 19 microsatellite markers, reported to be linked to drought. In this analysis, 6 primers were found to be polymorphic.PCR amplification of the 20 inbred lines with these 6 polymorphic primers (RM 1349, RM 3825, RM 212, RM 232, RM 24, RM 3) confirmed presence of drought tolerant QTLs. Line numbers 4, 122, 125, 135, 137, 152, 161, 162, $165,179,180,181,193,194,205,418,586,808,809$ and 810 were found to be drought tolerant based on drought screening and molecular study results. Several QTLs reported on chromosome 1, 3, 4, 5, 6, 7 and linked to drought traits like plant height, panicle length, grain yield, days to $50 \%$ flowering, biomass, harvest index and test weight were detected in different RILs. Rice cultivation is highly water-intensive. Drought is a major constraint affecting rice production especially in rain fed areas. The present study revealed the identification of drought tolerant inbred lines and presence of QTLs linked to drought. The study has identified lines that can be inter-crossed to enable pyramiding of different QTLs, which can then generate a mega variety for drought tolerance. Also, Marker Assisted Backcrossing and other methods can be used to introgress these identified QTLs in the desirable background.

\section{REFERENCES}

1. Babu, R.C., Nguyen, B.D., Chamarerk, V., Shanmugasundaram, P., Chezhian, P., Jeyaprakash, P., Ganesh, S.K., Palchamy, A., Sadasivam, S., Sarkarung, S., Wade, L.J. and Nguyen, H.T. 2003. Genetic analysis of drought resistance in rice by molecular markers: Association between secondary traits .and field performance. Crop Sci. 43:1457-1469.

2. Beena, R. 2005. Studies on physio-morphological traits and genetic markers associated with drought response in rice (OryzasativaL.). Ph. D. (Crop Physiology) thesis. Tamil Nadu Agricultural University, Coimbatore, India.

3. Bernier, J., Kumar, A., Ramaiah, V., Spaner, D. and Atlin, G. 2007. A large effect QTL for grain yield under reproductive stage drought stress in upland rice. Crop Sci. 47: 507-516.

4. Boopathi, N.M. 2004. Quantitative trait loci mapping of drought resistance traits in rice (OryzasativaL.) line adapted to target population of environment. Ph.D. (Biotechnology) thesis. Tamil Nadu Agricultural University, Coimbatore, India.

5. Hittalmani, S., Huang, N., Courtois, B., Venuprasad, R., Shashidhar, H.E., Bagali, G.G., Li, Z.K., Zhuang, J.Y., Zheng, K.L., Liu, G.F., Wang, G.C., Singh, V.P., Sidhu, J.S., Srivantaneeyakul, S., McLaren, G. and Khush, G.S. 2003. Identification of QTLs for growth and grain yield related traits in rice across nine locations in Asia. Theory. Applied Genet. 107: 679-690.

6. Kamoshita, A., Zhang, J., Siopongco, T., Sarkarung, S., Nguyen, H.T. and Wade, L.J. 2002. Effects of phenotypic environments on Identification of quantitative trait loci for rice root morphology under anaerobic conditions. CropSci.42: 255-265.

7. Kanagaraj, P., Prince, K.S.J., Sheeba, J.A., Biji, K.R., Paul, S.B., Senthil, A. and Chandra Babu, R. 2010. Microsatellite markers linked to drought resistance in rice (OryzasativaL.). Current Sci. 98(6): 25.

8. Lin, M.H., Lin, C.W., Chen, J.C., Lin, Y.C., Cheng, S.Y., Liu, T.H., Jan, F.J., Wu, S.T., Thseng, F.S. and Ku, H.M. 2007. Tagging rice drought-related QTL with SSR DNA markers. Crop Environ. Bioinfo. 4: 65-76.

9. Manickaveli, A., Gnanamalar., R.P., Nadarajan, N. and Ganesh, S.K. 2006. Genetic variability studies on different genetic populations of rice under drought condition. J. Plant Science. 1(4): 332-339.

10. Price, A.H., Steele, K.A., Moore, B.J., Barraclough, P.B. and Clark, L.J. 2000. A combined RFLP and AFLP map of upland rice (Oryzasativa L.) used to identify QTL for root penetration ability. Theor. Appl. Genet. 100: 49-56. 
11. Singh, V.N., Singh., A.K., Singh., B.B., Chaturvedi, G.S., Verma, O.P. and Atlin, G. 2004. In: Poland., D., Sawkins, J., Rabait, M.J., and Hoisinfron, D. Resilient crop for water limited environment: Proceeding of a workshop held at cuernavaca Mexico. May 24-28, 2004.

12. Steele, K.A., Price, A.H., Shashidhar, H.E. and Witcombe, J.R. 2006. Marker assisted selection to introgress rice QTLs controlling root traits into an Indian upland rice variety. Theor. Applied Genet.112: 208-221.

13. Venuprasad, V., Shashidhar, H.E. and Hittalmani, S. 2002. QTL Mapping of grain yield and related traits in rice in three diverse environment. Proceeding of $8^{\text {th }}$ National Rice 
